\title{
Anterior transpedicular screw fixation of cervical spine: Is it safe? Morphological feasibility, technical properties, and accuracy of manual insertion
}

\author{
Ender Koktekir, MD, ${ }^{1}$ Zafer Orkun Toktas, MD, ${ }^{2}$ Askin Seker, MD, ${ }^{3}$ Akin Akakin, MD, ${ }^{2}$ \\ Deniz Konya, MD, ${ }^{2}$ and Turker Kilic, $\mathrm{MD}, \mathrm{PhD}^{2}$ \\ ${ }^{1}$ Department of Neurosurgery, Selcuk University, Konya; ${ }^{2}$ Department of Neurosurgery, Bahcesehir University; and \\ ${ }^{3}$ Department of Neurosurgery, Marmara University, Istanbul, Turkey
}

\begin{abstract}
OBJECT Due to lack of construct stability of the current anterior cervical approaches, supplemental posterior cervical approaches are frequently employed. The use of an anterior-only approach with anterior transpedicular screws (ATPSs) has been proposed as a means of providing 3-column fixation. This study was designed to investigate the feasibility of anterior transpedicular screw (ATPS) fixation of cervical spine, to obtain the morphological measurements for technical prerequisites, and to evaluate the accuracy of the ATPS using fluoroscopy.

METHODS The study included both radiological and anatomical investigations. The radiological investigations were based on data from cervical spine CT scans performed in 65 patients. Technical prerequisites of ATPS were calculated using OsiriX for Mac OS. In the anatomical part of the study, 30 pedicles (C3-7) from 6 formalin-preserved cadavers were manually instrumented. Measurements obtained included pedicle width (PW), pedicle height (PH), pedicle transverse angle (PTA), distance of the entry point from the midline (DEPM), and distance of the entry point from the superior endplate (DEPSEP). The authors also analyzed screw position in the manually instrumented vertebrae.

RESULTS The mean PW and PH values showed a tendency to increase from C-3 to C-7 in both males and females. The means were significantly larger for both PW and PH in males than in females at all levels $(p=0.001)$. The overall mean PTA value was significantly lower at C-7 $(p<0.0001)$. The mean value for the distance of entry point from the midline (DEPM) represented a point at the contralateral side of the pedicle for every level except $C-7$. The mean DEPSEP values showed significant differences between all levels $(p<0.0001)$. Seven of the 30 screws were identified as breaching the pedicle (23.3\%); these screw malplacements were seen at C-3 (3 screws), C-4 (2 screws), and C-5 (2 screws).

CONCLUSIONS The morphological measurements of this study demonstrated that ATPS fixation is feasible in selected cases. They indicate that ATPS insertion using a fluoroscopy-assisted pedicle axis view is safe at the C-6 and C-7 levels, but the results at the other levels did not prove the safety of this technique.
\end{abstract}

http://thejns.org/doi/abs/10.3171/2014.10.SPINE14669

KEY WORDS anterior transpedicular screw fixation; fluoroscopy; accuracy; cervical; pedicle; anatomy

$\mathrm{S}$ INCE it was first described by Boucher in 1957, the use of transpedicular screw fixation to treat spinal instability has become an indispensable approach, especially in the thoracic and lumbar spine. However, its use in the cervical spine has remained controversial due to the potential risks of neurovascular injuries. Such concerns encouraged studies about its clinical use in light of anatomical and radiological knowledge and intraoperative imaging techniques. ${ }^{1,13}$
The clinical use of posterior cervical pedicle screw (PCPS) fixation was first described by Abumi et al. in 1994. ${ }^{1}$ Since then, several studies have demonstrated the superior biomechanical properties of the construct provided by PCPSs compared with those of other posterior cervical stabilization techniques, ${ }^{2,8,13}$ In contrast, the current stabilization techniques in anterior approaches are still challenging. Due to low pullout strength, high non-union rates, and the inferior biomechanical properties of anterior

ABBREVIATIONS ATPS = anterior transpedicular screw; DEPM = distance of the entry point from the midline; DEPSEP = distance of the entry point from the superior endplate; $\mathrm{PAL}=$ pedicle axis length; $\mathrm{PCPS}=$ posterior cervical pedicle screw; $\mathrm{PH}=$ pedicle height; $\mathrm{PTA}=$ pedicle transverse angle; $\mathrm{PW}=$ pedicle width; $\mathrm{VA}=$ vertebral artery. SUBMITTED July 20, 2014. ACCEPTED October 23, 2014.

INCLUDE WHEN CITING Published online March 27, 2015; DOI: 10.3171/2014.10.SPINE14669.

DISCLOSURE The authors report no conflict of interest concerning the materials or methods used in this study or the findings specified in this paper. 
plate-screw systems, the posterior approach is frequently employed, especially in patients with multilevel corpec-

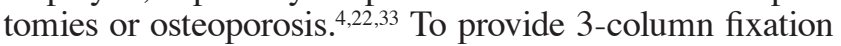
and decompression in the cervical spine through only an anterior approach, the concept of anterior transpedicular screw (ATPS) fixation was introduced by Koller et al. in $2008 .{ }^{18}$ Despite increasing reports in the last 5 years, the feasibility of this technique remains controversial, and the overall conclusion is that there is a need for additional studies. Therefore, the current study was designed to investigate the feasibility of ATPS fixation, to obtain the morphological measurements for technical prerequisites, and to evaluate the accuracy of ATPS placement using fluoroscopy.

\section{Methods \\ Radiological Investigation}

Data were collected from cervical spine CT scans performed in 65 patients who presented to the Selcuk University emergency department with neck pain. The group included 34 men and 31 women. The mean age of the women was $41.2 \pm 12.8$ years (range $21-67$ years) and that of the men, $46.5 \pm 11.9$ years (range $23-65$ years). Patients who had evidence of tumor, deformity, fracture, or severe degenerative changes on CT scans were excluded from the study. All studies were performed using the same CT scanner with a standard trauma protocol (1-mm axial slice thickness). All images were reconstructed in both the sagittal and coronal planes, and digital measurements were taken using the OsiriX DICOM viewer (Pixmeo) for Mac OS. The following parameters were measured at the relevant levels from $\mathrm{C}-3$ to $\mathrm{C}-7$ : pedicle width (PW, mediolateral diameter of the pedicle on the axial image), pedicle height $(\mathrm{PH}$, rostrocaudal diameter of the pedicle on the sagittal image), pedicle transverse angle (PTA, angle between the transverse pedicle axis and the midline of the vertebral body), pedicle sagittal angle (PSA, angle between the sagittal pedicle axis and the anterior vertebral body cortex), pedicle axis length (PAL, distance from the anterior vertebral body wall to the posterior surface of the lateral mass), distance of the entry point from the midline (DEPM, distance between the projection of a perpendicular line in the central corridor of the pedicle onto the anterior vertebral cortex and the midline, with distances from entry points contralateral to the pedicle given positive values and distances to points ipsilateral to the pedicle given negative values), distance of the entry point from the superior endplate (DEPSEP, distance between the projection of a perpendicular line in the central corridor of the pedicle onto the anterior vertebral cortex on a sagittal image and the superior endplate of the corresponding vertebral body) (Figs. 1 and 2).

\section{Anatomical Investigation}

The anatomical part of this study was performed in Professor Albert Rhoton's Microneurosurgery Laboratory at the Marmara University Neurological Science Institute. Six formalin-preserved cervicothoracic spines (C0-T2) were harvested from 4 male and 2 female cadavers. The mean age of the individuals at death was 72 years (range 68-79 years). All specimens' vertebral arteries (VAs) were
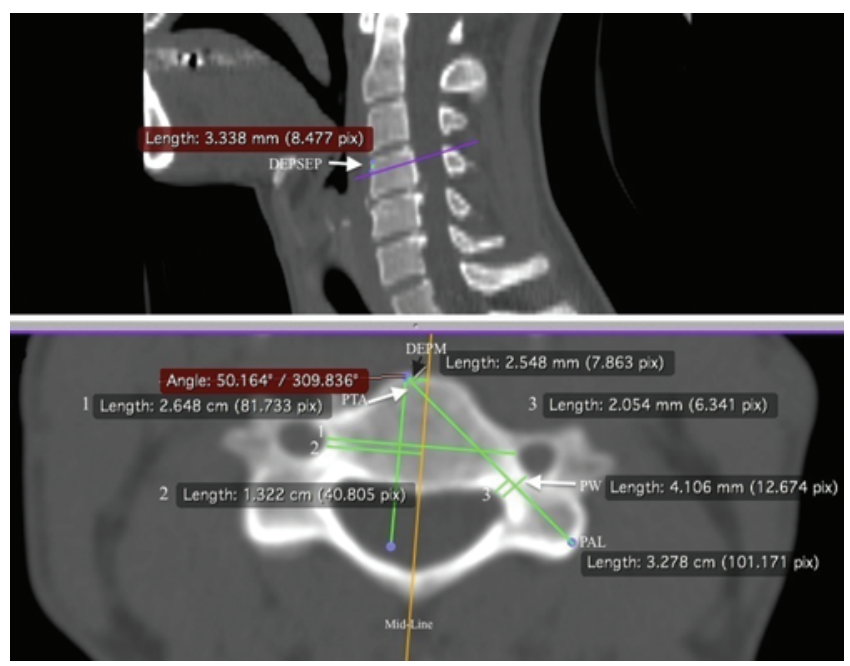

FIG. 1. Use of 3D curved multiplanar reconstruction (MPR) CT images for measurement of the entry points. Upper: Sagittal image showing the distance of the entry point from the superior endplate (DEPSEP, white arrow). Lower: Axial image showing the distance of the entry point from the midline (DEPM, black arrow), pedicle transvers angle (PTA, white arrow), pedicle width (PW, white arrow), and pedicle axis length (PAL). The midline was defined by the calculation of one-half (2) of the distance between the transverse foramina (1). The pedicle axis was defined by the calculation of the PW midpoint (3). pix = pixels. Figure is available in color online only.

filled with red dye before screw placement to direct visualization of the relationship between the screw position and the VA at the end of the procedure. To exclude any structural pathology or congenital deformations and to confirm the availability of sufficient pedicle thickness for screw placement, CT scans (1-mm slice thickness) were obtained
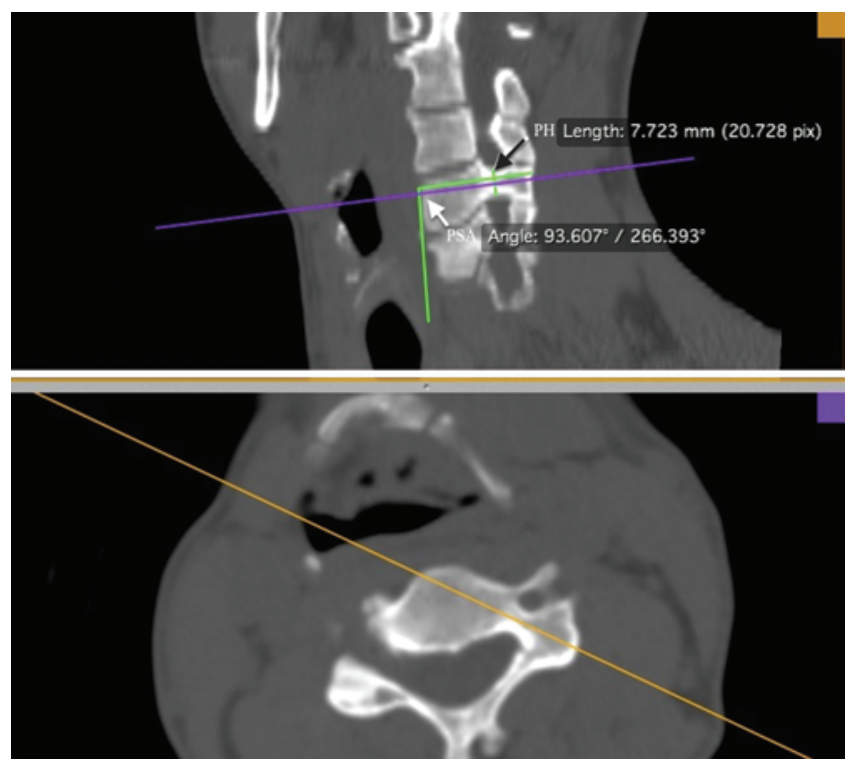

FIG. 2. Upper: Sagittal CT reconstruction showing the pedicle sagittal angle (PSA, white arrow) and pedicle height (PH, black arrow). Lower: The region of interest software option was used to reconstruct the pedicle axis line into the sagittal image. Figure is available in color online only. 
of all specimens. None of the specimens had evidence of structural pathology. The morphological data needed to perform ATPS were obtained.

\section{Surgical Procedure}

All screw placements were performed by the same surgeon (E.K.). Thirty cervical pedicles were instrumented. The diameter of the screws was $3.5 \mathrm{~mm}$. After the removal of all anterior soft tissues (from the skin to the longus colli muscles), the midsagittal line of the vertebral body was marked as the midpoint between the medial edges of the longus colli muscles. The estimated entry points were determined according to prior morphometric measurements and marked with small pins. Standard C-arm fluoroscopy was performed in accordance with previously described surgical procedures for posterior cervical pedicle screw fixation. ${ }^{17,37}$ Before the screw placement, the device was set to obtain a circular portion of the pedicle cortex (true lateral view). Thus the C-arm fluoroscopy device was rotated into the oblique position until it became perpendicular to the pedicle axis. After decortication of the screw entry point with a high-speed drill, a straight awl was used to create the tract for the pedicle screw under fluoroscopic confirmation. The trajectory was checked by means of a 1-mm pedicle probe, which indicated whether there was any encroachment. If the pedicle probe migrated outside the pedicle, another attempt was made at obtaining a correct trajectory using the same technique. The screw was inserted only after the tract had been checked and found to show no signs of encroachment. This procedure was repeated for each cervical level. The screws were $3.5 \mathrm{~mm}$ in diameter and $30 \mathrm{~mm}$ in length.

\section{Assessment of the Accuracy of Screw Placement}

The accuracy of ATPS placement was evaluated by both CT images and direct anatomical visualization of the screws. Medial and lateral malplacement was assessed on axial CT images, whereas inferior and superior malplacement was assessed on sagittal reconstructed images. To evaluate the accuracy, we used a modified grading system based on the classification scheme used by Koller et al., ${ }^{17}$ as presented in Table 1 .

After the CT evaluation of the screw accuracy, each vertebra was removed and examined to confirm the validity of the radiological evaluation. All vertebral bodies were drilled in the transverse plane until direct visualization of the screw and its relationship with the VA and spinal cord could be performed.

\section{Statistical Analysis}

An independent t-test was performed using SPSS 17.0 to compare the measurements obtained in males and females. A paired t-test was used to compare the right and left measurements of the males and the females. A p value lower than 0.05 was accepted as statistically significant.

\section{Results \\ Morphological Analysis}

The morphological measurements of 65 cervical spines
TABLE 1. Grading system for pedicle screw placement used in this study*

\begin{tabular}{cc}
\hline Grade & \multicolumn{1}{c}{ Description } \\
\hline 1 & Screw fully centered w/in pedicle \\
\hline $2 \mathrm{~A}$ & $\begin{array}{c}\text { Less than one-third of screw cross-section penetrating } \\
\text { cortex of pedicle in caudal or cranial direction }\end{array}$ \\
\hline $2 \mathrm{~B}$ & $\begin{array}{c}\text { At least one-third of screw cross-section penetrating cortex } \\
\text { of pedicle in caudal or cranial direction }\end{array}$ \\
\hline $3 \mathrm{~A}$ & $\begin{array}{c}\text { Less than one-third of screw cross-section penetrating } \\
\text { medial or lateral cortex of pedicle }\end{array}$ \\
\hline $3 \mathrm{~B}$ & $\begin{array}{c}\text { At least one-third of the screw cross-section penetrating the } \\
\text { medial or lateral cortex of the pedicle }\end{array}$ \\
\hline
\end{tabular}

* Based on the grading system used by Koller et al. ${ }^{17}$

comprising 325 vertebrae from C-3 to C-7 were evaluated. The means, standard deviations, and ranges are shown in Tables 2 and 3. None of the measurements showed statistically significant differences between the right and left sides $(\mathrm{p}>0.05)$.

\section{Pedicle Widths and Heights}

The mean pedicle width (PW) and pedicle height $(\mathrm{PH})$ showed a tendency to increase from C-3 to C-7 in both males and females. The means were significantly larger for both PW and PH in males than in females at all levels $(p=0.001)$. The mean PW ranged from 5.46 to $6.78 \mathrm{~mm}$ for males and from 4.48 to $5.83 \mathrm{~mm}$ for females, while the mean PH ranged from 6.73 to $8.16 \mathrm{~mm}$ for males and 5.69 to $6.92 \mathrm{~mm}$ for females. The frequencies of PW and $\mathrm{PH}$ values below $4 \mathrm{~mm}$ and $5 \mathrm{~mm}$ are shown in Table 4 .

\section{Pedicle Transverse Angle and Pedicle Sagittal Angle}

There were no statistically significant differences between the males and females $(\mathrm{p}>0.05)$ with respect to pedicle transverse angle (PTA) or pedicle sagittal angle (PSA). The overall mean PTA value ranged from $48^{\circ}$ to $50^{\circ}$ at the levels of C3-6. The overall mean PTA value was significantly lower $\left(38^{\circ}\right)$ at the level of C-7 (p < $0.0001)$. The overall mean PSA ranged from $92^{\circ}$ to $109^{\circ}$. The smallest mean value was at C-3 and the largest at C-6.

\section{Pedicle Axis Length}

The mean value of pedicle axis length (PAL) was greatest at C-7 both in males and in females (34.31 and 34.08 $\mathrm{mm}$, respectively). The mean value was smallest at C-6 in males $(33.78 \mathrm{~mm})$ and at C-5 in females $(33.53 \mathrm{~mm})$. There were no statistically significant differences between the levels or sexes $(p>0.05)$.

\section{Distance of Entry Points from the Midline and Superior Endplate}

The mean values for the distance of the entry point from the midline (DEPM) were at the contralateral side of the pedicle except at the level of C-7. The overall means showed no significant differences between the males and females or the left and right sides $(\mathrm{p}>0.05)$. The overall mean values ranged from 2 to $3 \mathrm{~mm}$ at $\mathrm{C} 3-6$. The overall 
TABLE 2. PTA, PSA, PL, DEPM, and DEPSEP measurements stratified by level*

\begin{tabular}{cccccc}
\hline Level & PTA $\left({ }^{\circ}\right)$ & PSA $\left({ }^{\circ}\right)$ & PL $(\mathrm{mm})$ & DEPM $(\mathrm{mm}) \dagger$ & DEPSEP $(\mathrm{mm})$ \\
\hline C-3 & $49.06 \pm 3.11(41.78-54.61)$ & $92.18 \pm 4.71(79.41-103.56)$ & $33.87 \pm 2.63(29.12-37.83)$ & $+2.87 \pm 1.28(1.46-4.04)$ & $2.86 \pm 0.92(1.32-4.11)$ \\
\hline C-4 & $50.22 \pm 3.73(46.31-54.23)$ & $98.33 \pm 5.02(83.86-108.07)$ & $33.91 \pm 2.32(30.11-37.06)$ & $+2.27 \pm 1.52(1.18-4.56)$ & $3.38 \pm 1.01(1.94-5.27)$ \\
\hline C-5 & $49.51 \pm 4.03(47.17-55.68)$ & $105.58 \pm 5.36(86.60-113.72)$ & $33.64 \pm 1.83(28.09-36.17)$ & $+2.74 \pm 1.11(1.58-3.83)$ & $4.57 \pm 1.23(2.28-6.19)$ \\
\hline C-6 & $48.32 \pm 3.64(45.64-53.85)$ & $109.37 \pm 4.93(98.75-118.59)$ & $33.72 \pm 2.26(28.93-38.81)$ & $+2.02 \pm 1.77(1.04-4.13)$ & $5.32 \pm 1.37(3.47-6.83)$ \\
\hline C-7 & $38.23 \pm 3.73(33.52-46.09)$ & $102.82 \pm 4.43(84.71-111.27)$ & $34.19 \pm 2.89(30.38-40.14)$ & $-1.16 \pm 1.08(-3.12-0.82)$ & $5.71 \pm 1.21(3.88-7.31)$ \\
\hline
\end{tabular}

* Values shown are mean \pm SD (range). The measurements of PTA, PSA, PL, DEPM, and DEPSEP showed no significant differences between the males and females or right and left sides $(p>0.05)$. The mean PTA was significantly smaller at $C-7$ than the other levels $(p<0.0001)$. The mean DEPSEP measurements showed significant differences between all levels $(p<0.0001)$. The mean DEPM measurements were at the contralateral side to the pedicle at all levels except $C 7$.

$\dagger$ A plus sign (+) indicates that the entry point is located at the contralateral side to the pedicle. A minus sign (-) indicates that the entry point is located at the ipsilateral side of the pedicle.

mean was $1.56 \mathrm{~mm}$ at $\mathrm{C}-7$ but on the ipsilateral side of the pedicle.

The mean values for the distance of the entry point from the superior endplate (DEPSEP) showed significant differences between all levels $(\mathrm{p}<0.0001)$. The overall means showed no significant differences between the males and females or the left and right sides $(p>0.05)$. The mean values ranged from 2.9 to $5.7 \mathrm{~mm}$. The mean value was lowest (i.e., reflecting an entry point closest to the superior endplate) at C-3.

\section{Accuracy of Pedicle Screw Placement in Cadaveric Specimens}

Thirty pedicles were instrumented. Preprocedure CT scans showed that all pedicle widths were larger than 4 $\mathrm{mm}$. According to postprocedure CT scans, 7 of the 30 screws were identified as breaching the pedicle (23.3\%). In 5 of these 7 instances, the accuracy of the screw placement was considered Grade 3A (71.4\%) and in 2 it was Grade 3B (28.6\%) (Table 5). The screw malplacements were seen

TABLE 3. Percentages of pedicles with widths greater than 4 or 5 $\mathrm{mm}$ at each vertebral level stratified by sex ${ }^{*}$

\begin{tabular}{ccc}
\hline Level & PW $(\mathrm{mm})$ & PH $(\mathrm{mm})$ \\
\hline C-3 & & \\
\hline Male & $5.46 \pm 0.70(3.86-6.59)$ & $6.73 \pm 0.81(5.31-7.03)$ \\
\hline Female & $4.48 \pm 0.56(3.67-5.72)$ & $5.69 \pm 0.68(4.91-6.61$ \\
\hline C-4 & \\
\hline Male & $5.55 \pm 0.71(3.84-6.69)$ & $6.89 \pm 0.93(5.28-7.21)$ \\
\hline Female & $4.70 \pm 0.69(3.57-6.15)$ & $5.93 \pm 0.84(5.08-6.69)$ \\
\hline C-5 & & \\
\hline Male & $5.73 \pm 0.70(3.85-6.96)$ & $7.26 \pm 1.12(5.54-8.11)$ \\
\hline Female & $4.75 \pm 0.75(3.61-6.24)$ & $6.16 \pm 1.06(5.43-7.19)$ \\
\hline C-6 & & \\
\hline Male & $5.98 \pm 0.59(5.09-7.36)$ & $7.53 \pm 1.17(6.18-8.84)$ \\
\hline Female & $5.12 \pm 0.63(4.09-6.67)$ & $6.53 \pm 1.11(5.51-8.02)$ \\
\hline C-7 & & \\
\hline Male & $6.78 \pm 0.67(5.24-8.21)$ & $8.16 \pm 1.09(6.74-9.94)$ \\
\hline Female & $5.83 \pm 0.62(4.79-7.14)$ & $6.92 \pm 0.94(6.11-8.32)$ \\
\hline
\end{tabular}

* The mean PW and PH showed statistically significant differences between the levels and sexes $(p=0.001)$. at C-3 (3 screws), C-4 (2 screws), and C-5 (2 screws). All pedicle perforations occurred laterally, and 2 of them obviously injured the VA.

\section{Discussion}

\section{Indications and Theoretical Advantages of ATPS}

The main reason for performing ATPS fixation is to create an immediate rigid fixation of the cervical spine after multilevel decompression, a setting in which the incidence of construct failure, the incidence of repeat surgeries, and the need for posterior supplemental stabilization is high with current anterior stabilization techniques. . $9,20,33^{2}$ Therefore, tumor- or trauma-related 3-column instability and multilevel corpectomies ( 2 or more levels) for degenerative and infection diseases, which call for combined anteroposterior stabilization, would be the clinical indications for this technique.

One of the major advantages of the ATPS technique is provision of 3-column fixation, which is the desired method for spine stabilization. This technique enables decompression of the spinal cord and maintains the stability with only an anterior approach without need for the posterior supplemental stabilization in patients with pathologies that can be addressed entirely from an anterior approach. ${ }^{5,17,36}$ ATPS can be performed with a standard anterior approach, which is less traumatic than the posterior approach as well as being more familiar. There is a lower complication rate because there is no damage to the paravertebral muscles and facet capsules, which may cause significant myofascial pain. ${ }^{37}$ The postoperative infection rate is also lower in anterior approaches than

TABLE 4. The rates of mean PW above 4 and $5 \mathrm{~mm}$ at each vertebral level stratified by sex

\begin{tabular}{cccccc}
\hline PW & C-3 (\%) & C-4 (\%) & C-5 (\%) & C-6 $(\%)$ & C-7 (\%) \\
\hline$>4 \mathrm{~mm}$ & & & & & \\
\hline Male & 94.1 & 94.1 & 100 & 100 & 100 \\
\hline Female & 77.4 & 83.9 & 90.4 & 100 & 100 \\
\hline$>5 \mathrm{~mm}$ & & & & & \\
\hline Male & 70.6 & 73.6 & 88.3 & 100 & 100 \\
\hline Female & 28.7 & 35.5 & 41.4 & 70.7 & 83.6 \\
\hline
\end{tabular}


TABLE 5. Accuracy of screw positions by vertebral level*

\begin{tabular}{|c|c|c|c|c|c|}
\hline Level & Grade 1 & $\begin{array}{c}\text { Grade } \\
2 \mathrm{~A}\end{array}$ & $\begin{array}{c}\text { Grade } \\
2 B\end{array}$ & Grade $3 A$ & Grade 3B \\
\hline$C-3(n=6)$ & 3 & - & - & 2 & 1 \\
\hline$C-4(n=6)$ & 4 & - & - & 1 & 1 \\
\hline$C-5(n=6)$ & 3 & - & - & 2 & - \\
\hline$C-6(n=6)$ & 6 & - & - & - & - \\
\hline$C-7(n=6)$ & 6 & - & - & - & - \\
\hline Total & $22(76.7 \%)$ & - & - & $5(16.6 \%)$ & $2(6.6 \%)$ \\
\hline
\end{tabular}

* Grade 1 represents the screw fully centered in the pedicle. Grade 2 and Grade 3 represent sagittal plane and axial plane malplacement, respectively. "A" and " $B$ " represent noncritical and critical pedicle breach, respectively.

in posterior approaches. ${ }^{20,36}$ Additionally, ATPS fixation may avoid the need for postoperative rigid cervical orthoses such as the halo vest fixation device or sterno-occipito-mandibular immobilization (SOMI) device in patients treated with multilevel corpectomy. ${ }^{35}$

\section{Literature Evidence of the Feasibility of ATPS Fixation and Biomechanical Stability}

The clinical application of ATPS fixation has been reported in a few clinical studies. Aramomi et al., Ikenaga et al., and Zhao et al. published their series comprising 9, 7, and 7 cases, respectively. ${ }^{5,12,38}$ They performed anterior corpectomy and ATPS fixation because of cervical myelopathy. There were no complications related to surgery. However, the screw placement was performed under direct visualization of the pedicle, which was already exposed by the corpectomy. The first clinical report of ATPS use with a plate system was reported by Yukawa et al. ${ }^{36}$ They did not perform the corpectomy in their cases and inserted the ATPSs in 6 patients with the aid of the fluoroscopy of the pedicle axis. There were no complications in their study. The accuracy rates ranged from $94 \%$ to $96 \%$ in all of these studies, and the critical pedicle perforation was not reported. However, the accuracy cannot yet be estimated reliably because of the small sample sizes of these studies.

The main concerns about ATPS fixation involve biomechanical properties such as pullout strength of the screw and the quality of the construct stability in patients with advanced instabilities. Koller et al. showed that the pullout strength of ATPSs is 2.5-fold that of vertebral body screws. ${ }^{17}$ With respect to the issue of biomechanical quality in advanced instabilities, Koller et al. evaluated the biomechanical stability of an ATPS-plate system in a 2-level corpectomy model where the nonunion rate is high without posterior augmentation. ${ }^{20}$ They compared the ATPS-plate system with anterior plate, lateral mass screw construct, unilateral and bilateral PCPS construct, and $360^{\circ}$ construct techniques, each used separately, in their study. This study revealed that all instruments but the anterior plate showed significant reduction of range of motion for all directions and there were no significant differences between the posterior-only constructs and the ATPS-plate system in flexion-extension and axial rotation. However, $360^{\circ}$ constructs were more stable than the ATPS-plate system and posterior-only construct in axial rotation. They concluded that the ATPS-plate system offered encouraging results with primary stability, comparing well to its clinically accepted posterior counterparts..$^{20}$

Spinal fusion rates are strongly correlated with the biomechanical stability of the construct. ${ }^{17}$ Clinical studies are available in the literature that showed satisfactory union rates with ATPS fixation. Aramomi et al. observed solid spinal fusion in 6 of their 7 patients. ${ }^{5}$ The mean time to fusion was 12.3 months. Yukawa et al. observed early bony union in all of their cases, and the mean follow-up period was 12 months. ${ }^{36}$ Zhao et al. observed early bony fusion in 4 of their 6 patients, but the maximum follow-up period was only 3 months in their study. ${ }^{38}$

\section{Evaluation of Morphological Feasibility of ATPS Fixation}

It has been shown that the mean values for pedicle width and height vary by sex, race, and respective cervical levels. ${ }^{6,14,35}$ In our study, the mean PW and PH values were greater in males than in females and constantly increased from the cephalad to the caudad, as reported in the literature. ${ }^{11,30,31}$ There were no significant differences between the right and left pedicles. The overall mean $\mathrm{PH}$ values were 1-2 mm greater than the PW values at all levels, as reported by Panjabi et al..$^{28}$ and Kareikovic et al. ${ }^{14}$ The overall mean PH ranged from 6.2 to $7.5 \mathrm{~mm}$ in their studies, resembling the observations of Onibokun et al. ${ }^{27}$ None of the PH measurements was below $4 \mathrm{~mm}$. In our study, the overall mean PW values ranged from 4.5 to 6.8 $\mathrm{mm}$ and the mean PW value was significantly greater at C-7. Chazono et al. ${ }^{6}$ and Onibokun et al. ${ }^{27}$ reported similar means. They reported an overall mean cervical PW ranging from 5.4 to $6.6 \mathrm{~mm}$ and 4.7 to $6.5 \mathrm{~mm}$, respectively. However, Sakamoto et al. ${ }^{32}$ and Chen et al. ${ }^{7}$ reported larger means ranging from 5.7 to $7.7 \mathrm{~mm}$ and 5.8 to $7.7 \mathrm{~mm}$, respectively. These differences might be due to samples containing different ethnic groups, as previously observed by Liu et al. ${ }^{24}$

In addition to PW, the frequency of the mean PW being greater than $4 \mathrm{~mm}$ is an important issue when considering ATPS placement because the desired rigid fixation can be achieved when the screw size is at least $3.5 \mathrm{~mm}$. The rate of neural or vascular injury also increases when the PW is less than $4 \mathrm{~mm}$. Our measurements showed that the rates of mean PW above $4 \mathrm{~mm}$ were $94.1 \%$ for C-3 and C-4 and $100 \%$ for C-5, C-6, and C-7 in males, whereas they were $77.3 \%$ for $\mathrm{C}-3,83.9 \%$ for $\mathrm{C}-4,90.4 \%$ for $\mathrm{C}-5$, and $100 \%$ for C-6 and C-7 in females. In consideration of the use $4.5-\mathrm{mm}$ screws, we also looked at the frequency of PW values greater than $5 \mathrm{~mm}$ and found significantly lower rates, especially in females (Table 5). Similar rates have been reported by Koller et al. ${ }^{18}$ and Onibokun et al. ${ }^{27}$ However, Chen et al. found no measurements below $4 \mathrm{~mm}$ in either males or females. ${ }^{7}$ Our study results and literature data suggest that the patient's sex, the level of intervention, and the patient's race should be taken into account when considering ATPS fixation. Our results also show that ATPS fixation would be more reliable at C-6 and C-7 than at higher levels in both sexes and at C-5 also in males. However, with the use of smaller-diameter screws, the other levels, especially in males, could be appropriate for ATPS fixation in selected patients. 
The measurement of PTA and PSA is challenging because determining the accurate pedicle axis is difficult. Onibokun et al. showed that the overall mean PTA was approximately $44^{\circ}$ from C-3 to C- 6 and $38^{\circ}$ for C-7 for PCPS insertion. ${ }^{27}$ Our mean PTA for C-3 to C-6 was larger $\left(49^{\circ}\right)$ than theirs and our value for C-7 $\left(38^{\circ}\right)$ was the same. Koller et al. reported similar means..$^{18}$ The overall mean PSA ranged from $92^{\circ}$ to $102^{\circ}$ in our study. Similar results have been published in the literature.$^{6,7,24}$ However, the mean PSA is less likely to be a limiting factor than the PTA because the PH is generally larger than the PW at all levels.

The one of the main advantages of ATPS over PCPS is the availability of bicortical screw purchase. The mean values of PAL ranged from 22 to $33 \mathrm{~mm}$ for PCPS fixation in the literature. Zhou et al. ${ }^{39}$ and Koller et al ${ }^{18}$ reported larger means, ranging from 32 to $33 \mathrm{~mm}$ and 34 to $35 \mathrm{~mm}$ for ATPS fixation, respectively. Our means were similar and ranged from 33 to $34 \mathrm{~mm}$. Our study results indicate that ATPS can provide a longer screw pathway than PCPS and thus create a stronger construct. We recommend the use of a minimum screw length longer than $34 \mathrm{~mm}$ for ATPS fixation to achieve bicortical screw purchase.

We described the entry points in both the sagittal and the coronal planes by calculating the distances from the upper endplate and the midline, respectively. We chose the projection of the center of a corridor formed by the cervical pedicles onto the anterior vertebral body cortex as the reference point. In our study, the mean DEPSEP decreased from the cephalad to the caudad. The mean value ranged from 3 to $5 \mathrm{~mm}$ at $\mathrm{C} 3-5$ and from 5 to $6 \mathrm{~mm}$ at C-6 and C-7. Our means were similar at C-3, C-4, and C-5 but smaller at C-6 and C-7 compared to the means reported by Koller et al. ${ }^{18}$ However, our means were similar at C-6 and C-7 but larger at C-3, C-4, and C-5 compared to the means reported by Chen et al. ${ }^{7}$ These differences might be due to the determination of the pedicle axis by the observers. In our study, the mean DEPM was located on the contralateral side at C-3 to C-6 and on the ipsilateral side at C-7, as reported in previous studies. The mean ranged from 2 to 3 $\mathrm{mm}$ from C-3 to C-6 and was $1 \mathrm{~mm}$ at C-7, similar to the values reported by Koller et al. ${ }^{18}$

\section{Evaluation of Screw Accuracy in Cadaveric Specimens}

Different grading systems have been used for the evaluation of pedicle screw accuracy. ${ }^{10,21}$ However, due to the unique anatomy of this region, the evaluation of screw accuracy in the cervical spine deserves attention. Three main anatomical structures-nerve roots (located inferior and superior to the pedicle), the spinal cord (located medial to the pedicle), and the VA (lateral to the pedicle) - may be injured as a result of pedicle screw malplacement. ${ }^{3,23}$ Obviously, injury to the spinal cord and the VA would be associated with higher morbidity than injury to the nerve roots. In this study, we modified an existing grading system. We defined Grade 2 screw malplacement as an inferior or superior pedicle breach and Grade 3 as screw malplacement with a medial or lateral pedicle breach. In our grading system, we added the "A" and "B" subgrades to describe minor (noncritical) and major (critical) pedicle breach, respectively.
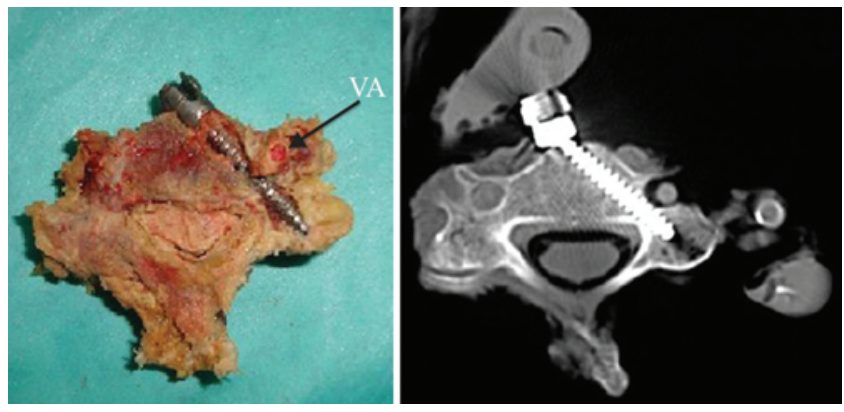

FIG. 3. Direct and radiological visualization of Grade I screw placement (screw fully centered in the pedicle). Left: Photograph showing the anatomical integrity of the VA (black arrow). Right: Axial CT image of vertebra after screw placement showing the medial and lateral shells of the pedicle are seen. Figure is available in color online only.

The accuracy of pedicle screw placement is usually evaluated with postoperative CT images. The major disadvantage of this method is exaggeration of the screw outline due to a metal artifact. ${ }^{16,29}$ In this study, we removed all vertebrae after radiological evaluation and drilled the bony structures until the relationship between the screw and the pedicle could be seen (Fig. 3). Although we observed some disproportional results between direct anatomical visualization and radiological evaluation (Fig. 4), we evaluated the pedicle screw accuracy according to postprocedure CT images to compare our results with those in the literature.

The rate of accuracy of PCPS ranged from 12\% to 97\% in the literature. ${ }^{2,18,25}$ The rate of noncritical pedicle breach has been reported as $72 \%$ on average, whereas critical pedicle breach is rarely reported..$^{3,21,26}$ Yukawa et al., in a report on their PCPS series published in 2006, ${ }^{37}$ observed that $17(4.0 \%)$ of 419 screws caused critical pedicle breach. The accuracy rates reported for ATPS placement range from $94 \%$ to $96 \%$ of ATPS. In a 2009 article, Yukawa et al. described their experience with the use of fluoroscopyassisted true pedicle axis images during ATPS insertion and reported that 16 (94.1\%) of 17 screws were placed accurately. ${ }^{36}$ However, they defined the screw accuracy as more than $50 \%$ of the screw diameter remaining in the pedicle. Aramomi et al. placed 22 ATPSs using oblique fluoroscopy in a series of 9 patients and reported an accuracy rate of $96 \%, 5$ although they did not mention the cri-
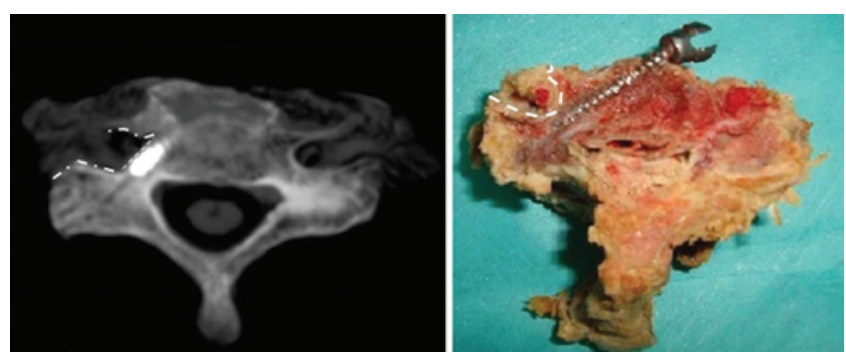

FIG. 4. Metallic artifact of the screw. Comparison of radiological evaluation (Grade 2B screw malplacement) and direct visualization of the screw placement at the same cervical level. Left: Axial CT image showing a lack of integrity (dotted line) of the transverse foramen due to lateral pedicle wall violation. Right: Photograph showing integrity of the transverse foramen. Figure is available in color online only. 
teria for evaluation of screw placement accuracy in their study. Zhao et al. reported their results for 14 screws. ${ }^{38}$ They used fluoroscopy-assisted pedicle axis images to perform ATPS fixation after corpectomy. They observed no pedicle perforation, but 1 screw exposure was found. Critical pedicle breach was not reported in any of these studies. The first anatomical study regarding the evaluation of the accuracy of manual ATPS insertion was published by Koller et al. ${ }^{17}$ They inserted 23 ATPSs in 6 cadaveric specimens using fluoroscopic assistance with pedicle axis images. In their study, the noncritical pedicle breach rate was $78 \%$ in the axial plane and $95.7 \%$ in the sagittal plane, whereas the critical breach rate was $21.7 \%$ in the axial plane and $4.4 \%$ in the sagittal plane. However, they defined noncritical pedicle breach as a screw centered in the pedicle or minor cortex deformation and screw threads less than one-third of the screw cross-section penetrating the cortex, whereas critical pedicle breach was defined as more than one-third of the screw cross section penetrating the cortex. Fu et al. used the same grading system to evaluate the screw accuracy in their anatomical study. ${ }^{9}$ They found that the noncritical breach rate was $91.7 \%$. However, they used the patient-specific biocompatible drill template to assist ATPS insertion. In the current study, all screw placements were performed using fluoroscopic assistance with true pedicle axis images, which were defined by $\mathrm{Yu}-$ kawa et al. ${ }^{36}$ The rate of accurate placement (screw fully centered in the pedicle) was $76.7 \%$, the rate of noncritical pedicle breach (less than one-third of the screw crosssection penetrating the cortex of the pedicle) was $16.6 \%$, and the rate of critical breach (more than one-third of the screw cross-section penetrating the cortex of the pedicle) was $6.6 \%$ in our study.

It has been shown that the main determinant of pedicle perforation is PW. ${ }^{10,34}$ The radiological part of our study confirmed that the cervical pedicle dimensions tend to increase in size from $\mathrm{C}-3$ to $\mathrm{C}-7$ and that the frequency of PW below $4 \mathrm{~mm}$ is higher at C-3, C-4, and C-5 than at C-6 and C-7. Karaikovic et al. ${ }^{15}$ and Ludwig et al. ${ }^{26}$ found that the rate of pedicle screw accuracy was $100 \%$ at C-7 in their PCPS series. Koller et al. reported a critical pedicle perforation rate of $0 \%$ at C-6 and C-7. ${ }^{17}$ Our study results were similar to those of previous studies. We observed that 7 of the 30 screws were malplaced, with the malplacements occurring at C-3 $(\mathrm{n}=3), \mathrm{C}-4(\mathrm{n}=2)$, and C-5 $(\mathrm{n}=$ 2). Critical pedicle breaches occurred at C-3 $(n=1)$ and C-4 $(n=1)$ (Fig. 5). The rate of screw placement accuracy was $100 \%$ at C-6 and C-7 in our study. Our study results suggest that ATPS insertion would be safer at C-6 and C-7.

Injury to neurovascular structures due to screw malplacement is the major concern associated with cervical pedicle screw placement. As shown in the previous studies and the current study, the width of the pedicles is typically less than the height, so the most common pedicle violation occurs in the transverse plane rather than in the sagittal plane. ${ }^{17,26}$ Several studies have shown that the incidence of screw malplacement in the lateral direction in the transverse plane is higher than in the medial plane due to the thinner lateral wall of the pedicle. ${ }^{10,37}$ In the current study, our results were similar. There was no screw malplacement in the sagittal plane. All 7 screw malplacements occurred

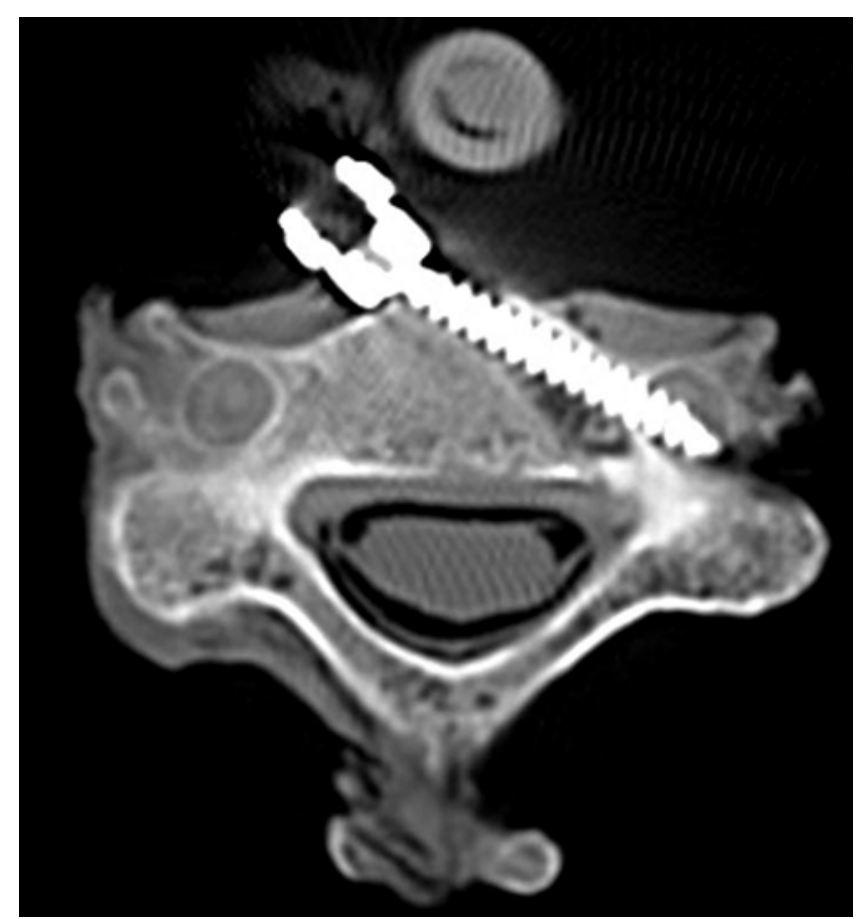

FIG. 5. Postprocedure CT scan showing obvious VA injury (Grade 3B screw malplacement).

in the lateral direction. Two of them obviously injured the VA, whereas the other screws did not cause VA obstruction. However, because of the high rate of lateral pedicle violation in our study, we suggest that CT or MR angiography should be performed to determine the dominant side of the VA (for selection of the side of intervention) before considering ATPS fixation.

\section{Limitations of ATPS Fixation}

Our study results and literature review revealed some limitations of this technique. First, our morphometric measurements showed that the ATPSs could only be inserted to one pedicle at each vertebral level because the entry points were located at the contralateral side at C3-6 and were very close to the midpoint at C-7. Although, unilateral screw placement may be associated with low biomechanical quality, Koller et al. showed that unilateral cervical pedicle screw fixation was sufficient to maintain a primary stability when compared with bilateral pedicle anchorage, even in advanced instabilities. ${ }^{20}$ Second, the high pedicle breach rate in this study $(23 \%)$ remains a concern with respect to the use of fluoroscopic guidance as an adjunctive technique for ATPS placement. Therefore we strongly recommend the use of intraoperative CT navigation systems, which help to determine the screw length and trajectory, especially at the levels of C-3, C-4, and C-5. Unfortunately, however, these systems may not be available because of cost issues. Third, due to proximity of the screw heads to the esophagus, rod-screw systems cannot be used with this approach. The current anterior plate systems are also not useful because the holes of the plate will not accommodate the ATPSs. Although, Yukawa et al. ${ }^{36}$ used the posterior plate system in their cases and Koller et 
al. ${ }^{20}$ described an ATPS-plate prototype, there is no currently accepted ATPS-plate system available for clinical application.

\section{Conclusions}

The results of our radiological and anatomical investigations and literature review demonstrate that ATPS fixation is feasible in selected cases. Selection of the cases should be based on the preoperative radiological evaluation especially focusing on the PW (i.e., whether it is greater than $4 \mathrm{~mm}$ ) and availability of intraoperative CT navigation. Based on our findings, we recommend the following morphological considerations for ATPS fixation: entrance points $2-3 \mathrm{~mm}$ from the midline on the contralateral side of the pedicle from C-3 to C-6 and $1 \mathrm{~mm}$ from the midline on the ipsilateral side of the pedicle at C-7, 3-5 $\mathrm{mm}$ from the superior endplate at the respective levels from C-3 to C-5, and 5-6 $\mathrm{mm}$ from the superior endplate at the respective levels at $\mathrm{C}-6$ and $\mathrm{C}-7$; transverse screw angle of $49^{\circ}$ from $\mathrm{C}-3$ to $\mathrm{C}-6$ and $38^{\circ}$ at C-7; sagittal screw angle of $90^{\circ}-100^{\circ}$ at all levels. Due to the high variability of PW between the sexes and vertebral levels, we recommend careful preoperative CT evaluation when considering ATPS fixation and the use of a screw at least $1 \mathrm{~mm}$ smaller than the pedicle size, if available. However, we suggest using a longer screw than the pedicle axis length to achieve bicortical purchase and thus a stronger construct. Our radiological data demonstrated that the entry points are located on the contralateral side of the pedicle except at C-7, which means that ATPS fixation can be performed on only 1 pedicle at each level. For this reason, we recommend that, due to the high incidence of lateral pedicle violation in our study, the dominant VA should be identified before deciding on the side for the pedicle insertion. The anatomical part of the study demonstrated that the insertion of ATPSs using a pedicle axis view with fluoroscopy is safe at the C-6 and C-7 levels, whereas our results at the other levels did not prove the safety of this technique. However, we believe that further studies using advanced imaging techniques such as computer-assisted navigation will prove the feasibility of ATPS fixation at the C-3, C-4, and C-5 levels.

\section{References}

1. Abumi K, Itoh H, Taneichi H, Kaneda K: Transpedicular screw fixation for traumatic lesions of the middle and lower cervical spine: description of the techniques and preliminary report. J Spinal Disord 7:19-28, 1994

2. Abumi K, Kaneda K, Shono Y, Fujiya M: One-stage posterior decompression and reconstruction of the cervical spine by using pedicle screw fixation systems. J Neurosurg 90 (1 Suppl):19-26, 1999

3. Abumi K, Shono Y, Ito M, Taneichi H, Kotani Y, Kaneda $\mathrm{K}$ : Complications of pedicle screw fixation in reconstructive surgery of the cervical spine. Spine (Phila Pa 1976) 25:962969,2000

4. Acosta FL Jr, Aryan HE, Chou D, Ames CP: Long-term biomechanical stability and clinical improvement after extended multilevel corpectomy and circumferential reconstruction of the cervical spine using titanium mesh cages. J Spinal Disord Tech 21:165-174, 2008

5. Aramomi M, Masaki Y, Koshizuka S, Kadota R, Okawa A,
Koda M, et al: Anterior pedicle screw fixation for multilevel cervical corpectomy and spinal fusion. Acta Neurochir (Wien) 150:575-582, 2008

6. Chazono M, Tanaka T, Kumagae Y, Sai T, Marumo K: Ethnic differences in pedicle and bony spinal canal dimensions calculated from computed tomography of the cervical spine: a review of the English-language literature. Eur Spine J 21:1451-1458, 2012

7. Chen C, Ruan D, Wu C, Wu W, Sun P, Zhang Y, et al: CT morphometric analysis to determine the anatomical basis for the use of transpedicular screws during reconstruction and fixation of anterior cervical vertebrae. PLoS ONE 8:e81159, 2013

8. Conrad BP, Cordista AG, Horodyski M, Rechtine GR: Biomechanical evaluation of the pullout strength of cervical screws. J Spinal Disord Tech 18:506-510, 2005

9. Fu M, Lin L, Kong X, Zhao W, Tang L, Li J, et al: Construction and accuracy assessment of patient-specific biocompatible drill template for cervical anterior transpedicular screw (ATPS) insertion: an in vitro study. PLoS ONE 8:e53580, 2013

10. Gelalis ID, Paschos NK, Pakos EE, Politis AN, Arnaoutoglou CM, Karageorgos AC, et al: Accuracy of pedicle screw placement: a systematic review of prospective in vivo studies comparing free hand, fluoroscopy guidance and navigation techniques. Eur Spine J 21:247-255, 2012

11. Gupta R, Kapoor K, Sharma A, Kochhar S, Garg R: Morphometry of typical cervical vertebrae on dry bones and CT scan and its implications in transpedicular screw placement surgery. Surg Radiol Anat 35:181-189, 2013

12. Ikenaga M, Mukaida M, Nagahara R, Yasunaga T, Ueda Y, Sohma Y: Anterior cervical reconstruction with pedicle screws after a 4-level corpectomy. Spine (Phila Pa 1976) 37:E927-E930, 2012

13. Jones EL, Heller JG, Silcox DH, Hutton WC: Cervical pedicle screws versus lateral mass screws. Anatomic feasibility and biomechanical comparison. Spine (Phila Pa 1976) 22:977-982, 1997

14. Karaikovic EE, Daubs MD, Madsen RW, Gaines RW Jr: Morphologic characteristics of human cervical pedicles. Spine (Phila Pa 1976) 22:493-500, 1997

15. Karaikovic EE, Yingsakmongkol W, Gaines RW Jr: Accuracy of cervical pedicle screw placement using the funnel technique. Spine (Phila Pa 1976) 26:2456-2462, 2001

16. Kim HS, Heller JG, Hudgins PA, Fountain JA: The accuracy of computed tomography in assessing cervical pedicle screw placement. Spine (Phila Pa 1976) 28:2441-2446, 2003

17. Koller H, Acosta F, Tauber M, Fox M, Martin H, Forstner $\mathrm{R}$, et al: Cervical anterior transpedicular screw fixation (ATPS)-Part II. Accuracy of manual insertion and pull-out strength of ATPS. Eur Spine J 17:539-555, 2008

18. Koller H, Hempfing A, Acosta F, Fox M, Scheiter A, Tauber $\mathrm{M}$, et al: Cervical anterior transpedicular screw fixation. Part I: Study on morphological feasibility, indications, and technical prerequisites. Eur Spine J 17:523-538, 2008

19. Koller H, Hempfing A, Ferraris L, Maier O, Hitzl W, MetzStavenhagen P: 4- and 5-level anterior fusions of the cervical spine: review of literature and clinical results. Eur Spine J 16:2055-2071, 2007

20. Koller H, Schmidt R, Mayer M, Hitzl W, Zenner J, Midderhoff $\mathrm{S}$, et al: The stabilizing potential of anterior, posterior and combined techniques for the reconstruction of a 2-level cervical corpectomy model: biomechanical study and first results of ATPS prototyping. Eur Spine J 19:2137-2148, 2010 (Erratum in Eur Spine J 20:1579, 2011)

21. Kosmopoulos V, Schizas C: Pedicle screw placement accuracy: a meta-analysis. Spine (Phila Pa 1976) 32:E111-E120, 2007

22. Kotani Y, Cunningham BW, Abumi K, McAfee PC: Biome- 
chanical analysis of cervical stabilization systems. An assessment of transpedicular screw fixation in the cervical spine. Spine (Phila Pa 1976) 19:2529-2539, 1994

23. Kotil K, Akçetin MA, Savas Y: Neurovascular complications of cervical pedicle screw fixation. J Clin Neurosci 19:546551,2012

24. Liu J, Napolitano JT, Ebraheim NA: Systematic review of cervical pedicle dimensions and projections. Spine (Phila Pa 1976) 35:E1373-E1380, 2010

25. Ludwig SC, Kramer DL, Balderston RA, Vaccaro AR, Foley KF, Albert TJ: Placement of pedicle screws in the human cadaveric cervical spine: comparative accuracy of three techniques. Spine (Phila Pa 1976) 25:1655-1667, 2000

26. Ludwig SC, Kramer DL, Vaccaro AR, Albert TJ: Transpedicle screw fixation of the cervical spine. Clin Orthop Relat Res (359):77-88, 1999

27. Onibokun A, Khoo LT, Bistazzoni S, Chen NF, Sassi M: Anatomical considerations for cervical pedicle screw insertion: the use of multiplanar computerized tomography measurements in 122 consecutive clinical cases. Spine J 9:729-734, 2009

28. Panjabi MM, Shin EK, Chen NC, Wang JL: Internal morphology of human cervical pedicles. Spine (Phila Pa 1976) 25:1197-1205, 2000

29. Rao G, Brodke DS, Rondina M, Dailey AT: Comparison of computerized tomography and direct visualization in thoracic pedicle screw placement. J Neurosurg 97 (2 Suppl):223-226, 2002

30. Rao RD, Marawar SV, Stemper BD, Yoganandan N, Shender BS: Computerized tomographic morphometric analysis of subaxial cervical spine pedicles in young asymptomatic volunteers. J Bone Joint Surg Am 90:1914-1921, 2008

31. Ruofu Z, Huilin Y, Xiaoyun H, Xishun H, Tiansi T, Liang C, et al: CT evaluation of cervical pedicle in a Chinese population for surgical application of transpedicular screw placement. Surg Radiol Anat 30:389-396, 2008

32. Sakamoto T, Neo M, Nakamura T: Transpedicular screw placement evaluated by axial computed tomography of the cervical pedicle. Spine (Phila Pa 1976) 29:2510-2515, 2004

33. Sasso RC, Ruggiero RA Jr, Reilly TM, Hall PV: Early reconstruction failures after multilevel cervical corpectomy. Spine (Phila Pa 1976) 28:140-142, 2003
34. Shin EK, Panjabi MM, Chen NC, Wang JL: The anatomic variability of human cervical pedicles: considerations for transpedicular screw fixation in the middle and lower cervical spine. Eur Spine J 9:61-66, 2000

35. Uğur HC, Attar A, Uz A, Tekdemir I, Egemen N, Cağlar S, et al: Surgical anatomic evaluation of the cervical pedicle and adjacent neural structures. Neurosurgery 47:1162-1169, 2000

36. Yukawa Y, Kato F, Ito K, Nakashima H, Machino M: Anterior cervical pedicle screw and plate fixation using fluoroscope-assisted pedicle axis view imaging: a preliminary report of a new cervical reconstruction technique. Eur Spine J 18:911-916, 2009

37. Yukawa Y, Kato F, Yoshihara H, Yanase M, Ito K: Cervical pedicle screw fixation in 100 cases of unstable cervical injuries: pedicle axis views obtained using fluoroscopy. J Neurosurg Spine 5:488-493, 2006

38. Zhao LJ, Xu RM, Jiang WY, Ma WH, Xu NJ, Hu Y: A new technique for anterior cervical pedicle screw implantation. Orthop Surg 3:193-198, 2011

39. Zhou RP, Jiang J, Zhan ZC, Zhou Y, Liu ZL, Yin QS: Morphological character of cervical spine for anterior transpedicular screw fixation. Indian J Orthop 47:553-558, 2013

\section{Author Contributions}

Conception and design: Koktekir, Toktas, Kilic. Acquisition of data: Koktekir, Toktas, Akakin. Analysis and interpretation of data: Koktekir. Drafting the article: Koktekir. Critically revising the article: Seker, Konya, Kilic. Reviewed submitted version of manuscript: Koktekir. Approved the final version of the manuscript on behalf of all authors: Koktekir. Administrative/techni$\mathrm{cal} /$ material support: Toktas, Akakin. Study supervision: Seker, Konya, Kilic.

\section{Correspondence}

Ender Koktekir, Department of Neurosurgery, Selcuk University, Alaaddin Keykubat Campus, Konya 42100, Turkey. email: enderkoktekirnrs@hotmail.com. 